tonnes of carbon dioxide annually in the 1990s and early 2000s. That's enough to more than offset the European Union's carbon emissions during the same period.

This effect is baked into many of the climate models that researchers use to project future global-warming scenarios. However, a study published in Nature this week suggests that the benefits from this tropical carbon 'sink' might be fleeting (W. Hubau et al. Nature 579, 80-87; 2020). And that could mean the international community will need to pledge yet faster emissions reductions if the world is to limit global warming to below $2{ }^{\circ} \mathrm{C}$, in line with the 2015 Paris climate agreement.

An international team led by geographers from the University of Leeds, UK, reports on page 80 that the Amazon rainforest has been absorbing less atmospheric carbon each year since the early 1990s. Forests in Africa have also been absorbing less atmospheric carbon since around 2015. This is due in large part to rising tree mortality.

Trees are dying, the researchers found, because temperatures are rising and drought is increasing, a trend that is likely to continue as greenhouse gases build up. A decade from now, Africa's carbon sink will be $14 \%$ lower compared with 2010-15. The Amazonian carbon sink is on course to disappear completely by 2035 . If that happens it will result in more carbon dioxide in the atmosphere, and therefore more global warming.

As we reported in a Feature last week, the Amazon's 5 million square kilometres look more precarious than ever (see Nature 578, 505-507; 2020). Average temperatures in this rainforest, which spans nine countries, have risen by $1-1.5^{\circ} \mathrm{C}$ over the past century; there have been three severe droughts since 2005 and tree clearing has shrunk the forest by $15 \%$ since the 1970 s. Brazil, once praised for its efforts in slowing deforestation, lost 10,000 square kilometres last year - the largest drop for a decade. A ten-year ban on planting sugar cane in the Amazon was lifted last November; and a bill to regulate oil and mining exploration is making its way to the national congress, Brazil's parliament.

In September, independent researchers from the region formed a science panel to propose what needs to be done to conserve the Amazon. The panel hasn't yet completed its report, but its overarching message cannot be in doubt: Brazil and other tropical nations need to halt deforestation and promote new forests in degraded - and often abandoned - lands.

At November's summit of the United Nations Framework Convention on Climate Change in Glasgow, UK, participating countries will be expected to redouble their pledges to meet the Paris climate agreement's goals. If tropical carbon sinks can no longer be fully relied upon to help reach that target, it means more ambitious decarbonization will be needed.

At the same time, the lesson for governments around the world is clear enough: tropical forests are working for humanity - and for countless other creatures. To protect them, humanity must halt both deforestation and global warming.

\title{
China changes tack
}

\section{A new researcher-evaluation system must not reduce international collaborations.}

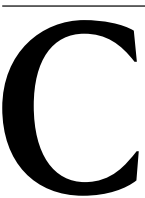

hina's researchers and research institutions are evaluated, ranked and funded according to their record of publishing in journals covered by the Science Citation Index (SCI), an international database of articles and citation records for around 9,000 journals.

The number of articles in these journals by authors at Chinese institutions increased nearly fourfold between 2009 and 2019. In that time, China's researchers have increased international collaborations, which have helped them secure international publications. But there have been concerns that widespread use of publication metrics incentivizes lower-quality work, as does the fact that some institutions pay bonuses to those publishing in journals.

But that might be about to change. Last month, the Chinese government ordered institutions to stop promoting or recruiting solely on the basis of number of papers or citations, and to end publishing bonuses (see page 18).

Research will still be evaluated, but institutions have until the end of July to propose new indicators. An alternative system will need to measure research quality and innovation, and whether something represents a significant advance or helps to solve an important societal problem. Evaluators will need to rely more on peer judgement, and, crucially, researchers must consider publishing in non-SCI-indexed journals.

The change is significant, and intended to meet two important government objectives. First, it is designed to help root out plagiarism, self-citation and colleagues citing each others' work to boost their citations. Second, it is aimed at boosting China's own research-publishing industry, which the government has wanted to do - but which is difficult if the best research is published internationally.

To enable more domestic research publishing, the government last year allocated one billion yuan (US\$143 million) over 5 years to improve the standards of some 280 Chinese journals, most of which publish in English. These journals have been ranked, with each of the top 22 receiving between one million and five million yuan annually to help them attract a higher standard of submissions, not only from China, but from around the world.

When this policy was announced, it wasn't known how the publishers would use their subsidy or how the government would measure success. The answers to both questions are now clearer.

China's government is urging its researchers to play their part by publishing in home-grown journals. That is important, not least because it will make science more accessible in China. But in setting up the new evaluation system, the government must be careful to protect the collaborations - and the relationships - that came with the old. 